The current study found that risperidone gave a greater overall reduction of scores on PANSS at 90 days than did either olanzapine or quetiapine (see also Lindenmayer et al, 2003).

A double-blind comparison of olanzapine and quetiapine in the treatment of patients with schizophrenia and schizoaffective disorder showed that both medications improved symptoms, with similar response rates. Olanzapine appeared to be better than quetiapine on overall PANSS response, while quetiapine was significantly better than olanzapine on the disorientation scale only. In terms of side-effects, quetiapine appeared to have a lesser effect on prolactin levels. Both medications caused weight gain (Svesta et al, 2003).

Another study has compared olanzapine with risperidone in relation to serum prolactin levels. A significantly lower proportion of patients receiving olanzapine experienced an elevation above standard reference ranges in prolactin concentration (51.2\% v. 94.4\%) (Tran et al, 1997). The present study found a similar trend.

One study showed that both olanzapine and risperidone were effective, but with olanzapine apparently significantly more effective. Both medications were associated with a $2 \mathrm{~kg}$ weight gain during the course of the study (Svesta et al, 2003). These results are in line with those of the current study.

The current study also found at 90 days a $46 \%$ reduction in PANSS score with risperidone, compared with 36\% with olanzapine. An 8-week study randomly allocated patients to quetiapine (400-800 mg/day), olanzapine (10-20 mg/day) or risperidone (4-8 mg/day). The quetiapine group had a $31 \%$ improvement in PANSS score, while the olanzapine group had a $25 \%$ improvement and the risperidone group a $21 \%$ improvement. Weight gain was more prominent with olanzapine: $36 \%$ of the patients had a weight gain of $>5 \%$ from baseline, compared with $17 \%$ of the risperidone patients and
$13 \%$ of the quetiapine patients (Sachetti et al, 2003). The present study had similar results.

\section{References}

Allison, D. B., Mentore, J. L., Heo, M., et al (1999) Antipsychotic-induced weight gain: a comprehensive research synthesis. American Journal of Psychiatry, 156, 1686-1696.

American Diabetes Association (2004) Consensus development conference on antipsychotic drugs and obesity and diabetes. Diabetes Care, 27, 596-601.

Breier, A., Berg, P. H., Thakore, J. H., et al (2005) Olanzapine versus ziprasidone: results of a 28-week double-blind study in patients with schizophrenia. American Journal of Psychiatry, 162, 1879.

Bryden, K. E. \& Kopala, L. C. (1999) Body mass index increase of $58 \%$ associated with olanzapine. American Journal of Psychiatry, 156, 1835-1836.

Gupta, S., Masand, P. S. \& Virk, S. (2004) Weight decline in patients switching from olanzapine to quetiapine. Schizophrenia Research, 70, 57-62.

Lindenmayer, J. P., Czobor, P., Volavka, J., et al (2003) Changes in glucose and cholesterol levels in patients with schizophrenia treated with typical or atypical antipsychotics. American Journal of Psychiatry, 160, 290-296.

Sachetti, E., Valsecchi, P. \& Regeni, C. (2003) Comparison of quetiapine, olanzapine and risperidone in patients with schizophrenia: interim results of a randomised, rater-blinded study. European Neuropsychopharmacology, 13, S350.

Straker, D., Correll, C. U. \& Kramer-Ginsberg, E. (2005) Cost effective screening for the metabolic syndrome in patients treated with second generation antipsychotic medication. American Journal of Psychiatry, $162,1217-1221$.

Svesta, J., Synek, O. \& Zourkova, A. (2003) A double-blind comparison of olanzapine and quetiapine in the treatment of acute exacerbations of schizophrenic disorders. European Neuropsychopharmacology, 13, S291.

Taylor, D. M. \& McAskill, R. (2000) Atypical antipsychotics and weight gain - a systematic review. Acta Psychiatrica Scandinavica, 101, 416-432.

Tran, P. V., Hamilton, S. H. \& Kuntz, A. J. (1997) Double blind comparison of olanzapine versus risperidone in the treatment of schizophrenia and other psychotic disorders. Journal of Clinical Psychopharmacology, $17,407-418$.

\title{
Use of herbal medications among out-patients in a psychiatry clinic in Sri Lanka
}

\section{K. A. L. A. Kuruppuarachchi ${ }^{1}$ and A. Hapangama²}

1Professor of Psychiatry, Faculty of Medicine, University of Kelaniya, Ragama, Sri Lanka, email lalithkuruppu@lycos.com ${ }^{2}$ Lecturer in Psychiatry, Faculty of Medicine, University of Kelaniya, Ragama, Sri Lanka

\begin{abstract}
The use of complementary and alternative medicine is increasing among psychiatric populations. Herbal medications are a form of alternative and complementary medicine whose use has increased over the last decade. Two studies done among Western out-patient groups have reported rates of use of herbal medicine at $15 \%$ ('current use'; Matthews et al, 2003) and 24\% (Knaudt et al, 1999).

Eastern cultures have a long tradition of using herbal medicines for a variety of conditions and people on the Indian subcontinent, for example, seem to be very familiar with
\end{abstract}

them. Concomitant use of herbal and Western medications is commonly observed even in the West. Herbal preparations contain biologically active components, with unique sideeffect profiles (Matthews et al, 2003). There have been reports of clinically significant interactions between herbs and Western medications (Fugh-Berman, 2000). In a US study of patients who used alternative therapies, only $38.5 \%$ had discussed this with their physician (Eisenberg et al, 1998).

However, there is limited information available on the prevalence of use of herbal medications, the types of plants 
Table 1 Prevalence of use of herbal medications by diagnosis

$\begin{array}{lccc}\text { Diagnosis } & \begin{array}{l}\text { Total number of } \\ \text { patients }\end{array} & \begin{array}{l}\text { Number who had previously } \\ \text { used herbal medications }\end{array} & \begin{array}{l}\text { Number currently using } \\ \text { herbal medications }\end{array} \\ \text { Depressive disorder } & 29 & 14 & 5 \\ \text { Bipolar affective disorder } & 13 & 3 & 1 \\ \text { Schizophrenia } & 18 & 2 & 2 \\ \text { Neurotic/stress related } & 3 & 2 & 1 \\ \text { Dementia } & 5 & 3 & 1 \\ \text { Delusional disorder/acute psychotic disorder } & 33 & 30 & 1 \\ \text { Substance use disorders } & 108 & 11\end{array}$

used or the reasons for their use, especially in low- and middle-income countries. We have carried out a preliminary study among psychiatric out-patients in Sri Lanka.

\section{Methods}

The objectives were to determine:

the prevalence of the use of herbal medicines among psychiatric out-patients

o patients' awareness of possible interactions between herbal and psychotropic medications

the reasons for the use of such medications

whether the use of herbal medications had been elicited by medical officers in their assessment of the patients.

We carried out a cross-sectional descriptive preliminary study using a pre-tested interviewer-administered questionnaire. The study participants were 108 consecutive patients who attended the out-patient psychiatric clinic, during 1 week, at the North Colombo Teaching Hospital, Ragama, Sri Lanka.

Patients were interviewed after they had given their written informed consent and after diagnosis according to ICD-10 criteria (World Health Organization, 1992).

\section{Results}

Of the 108 out-patients in the sample, 30 (28\%) had previously used herbal medicines and 11 (10\%) were currently using them. Table 1 gives a breakdown of prevalence by diagnosis.

Of those patients who used herbal medications, 63\% were female. Sixty-two per cent had used an oral form of herbal medication, while the rest had used it topically. Seventy-one per cent of these patients did not know the contents or the type of herbal medicine they were using or used, and $68 \%$ were not aware that there could be interactions between herbal and psychotropic medications. Table 2 shows the reasons given by the patients for the use of herbal medicine.

Table 2 Reasons for the use of herbal medicine

\begin{tabular}{ll} 
Reason given by the patient & Percentage \\
\hline As an adjunct to Western medication & 53 \\
Herbal medicines reduce the side-effects of & 62 \\
$\quad$ Western medications & \\
Accepted by relatives/peers & 41 \\
Herbal medications are natural & 32 \\
There is a better understanding how herbal & 25 \\
medicines act & 11 \\
No response to Western medications &
\end{tabular}

Fifty-nine per cent of this patient group had not told their psychiatrist about the use of herbal medication, and 69\% indicated that their psychiatrist had not asked them about the use of herbal medications.

\section{Discussion}

In our study, $28 \%$ of the out-patient sample had used herbal medicines at some point during their experience of mental disorder, while $10 \%$ were currently using them. The figures are somewhat lower than the proportions reported in studies among psychiatric out-patients in the West, although the general assumption is that in Eastern cultures people tend to use more complementary medicine than in the West. In our survey about a fifth of patients with affective disorders had used herbal medications. A study done in the USA demonstrated that the majority of patients with self-defined anxiety or severe depression used some form of complementary or alternative therapy (Kessler et al, 2001). However, our sample size was too small for any firm conclusion to be drawn regarding type of diagnosis and use of herbal medications.

The herbal medications used typically include St John's Wort for depression (Kessler et al, 2001), kava kava (Kessler et al, 2001) for mild anxiety, valerian (Werneke et al, 2006) as a sedative and Gingko biloba (Werneke et al, 2006) as a cognitive enhancer.

In our study, a majority of the patients did not know that there can be interactions between herbal and psychotropic medications. Of those taking herbal medicines, 53\% had used them as an adjunct to Western medication and $62 \%$ to reduce the side-effects of Western medications. Lack of awareness of the nature of the herbal medications can have deleterious consequences; for instance, some ingredients such as cannabis can precipitate or induce psychiatric problems. There are reports that Sri Lankan Ayurvedic preparations contain cannabis (Liyanage, 2004) and other psychoactive compounds, such as opioids (Government of Sri Lanka, 2007). The traditional Ayurveda and Unani-Tibbi medicine systems have used opium and cannabis as therapeutic agents for centuries (Dwarakanth, 1965).

Fifty-nine per cent of the patients had not told their psychiatrist about the use of herbal medication, and 69\% indicated that their psychiatrist had not asked them about their use.

\section{Conclusion}

A significant proportion of out-patients with mental disorders had used or were currently using herbal medications. It is important for psychiatrists to ask all patients about the 
use of herbal medications and to provide their patients with information about the potentially dangerous interactions between herbal and psychotropic medications. More research is needed into the prevalence of use of herbal medicines, the types of medicine used and drug-herb interactions. Patients' use of alternative therapies, including herbs, should be emphasised more in medical curricula, to increase awareness among medical professionals.

\section{References}

Dwarakanth, S. C. (1965) Use of opium and cannabis in the traditional systems of medicine in India. Bulletin on Narcotics. United Nations Office on Drugs and Crime.

Eisenberg, D. M., Davis, R. B., Ettnet, S. L., et al (1998) Trends in alternative medicine use in the United States, 1990-1997. Results of a follow-up national survey. JAMA, 280, 1569-1575.
Fugh-Berman, A. (2000) Herb-drug interactions. Lancet, 355, 134-138. Government of Sri Lanka (2007) Sri Lanka to totally eliminate drug abuse by 2010. Official Government News Portal of Sri Lanka, http://www. news.lk, 12 April.

Kessler, R. C., Soukup, J., Davis, R. B., et al (2001) The use of complementary and alternative therapies to treat anxiety and depression in the United States. American Journal of Psychiatry, 158, 289-294.

Knaudt, P. R., Connor, K. M., Weisler, R. H., et al (1999) Alternative therapy use by psychiatric outpatients. Journal of Nervous and Mental Disease, 187, 692-695.

Liyanage, K. J. (2004) Cannabis cultivation: relaxing the strong arm of the law. Observer, 23 May.

Matthews, S. C., Camacho, A., Lawson, K., et al (2003) Use of herbal medications among 200 psychiatric outpatients: prevalence, patterns of use, and potential dangers. General Hospital Psychiatry, 25, 24-26.

Werneke, U., Turner, T. \& Priebe, S. (2006) Complementary medicines in psychiatry. Review of effectiveness and safety. British Journal of Psychiatry, 188, 109-121.

World Health Organization (1992) International Classification of Diseases (10th revision) (ICD-10). WHO.

\section{RCPsych at the APA meeting in Washington - May 2008}

The College held its annual reception, organised by the PanAmerican Division, at the meeting of the American Psychiatric Association (APA), on 5 May 2008 at the Marriott Hotel. The President of the College, Sheila Hollins, updated the nearly 100 attendees on the College and psychiatric issues in Britain and Ireland; she went on to introduce her successor, Dinesh Bhugra, as well as Rachel Jenkins, Director of International Affairs, who spoke of the success of College educational efforts in Kenya and Iraq, despite severe poverty and major political problems, and Peter Tyrer, Editor of the British Journal of Psychiatry, who spoke of its increased scope and recognition and who ended with a Shakespearean epilogue!

The President of the APA, Carolyn Robinowitz, spoke of her shared passion for advocacy with Sheila Hollins and of the joint presidential symposium on this subject. There was also a joint symposium on education and the Pan-American Division held its seventh annual symposium, with six speakers from the International Divisions of the College, on poverty and mental illness around the world. There were members at the reception from all over the USA, Canada, Jamaica and Venezuela. It was also attended by the President-Elect of the Latin American Psychiatric Association, the Chairs of at least two other International Divisions, the Secretary of the Japanese Psychiatric Association, and many officers, trustees and former Presidents of the APA. It was a great social occasion and an important opportunity for networking and cooperation, which continued with other shared activities.

Anyone interested in next year's symposium at the APA or the Pan-American Division session at the College annual meeting should contact Nigel Bark, Chair, Pan-American Division, on panamericandivision@rcpsych.ac.uk.

Dr Nigel Bark

Chair, Pan-American Division, Royal College of Psychiatrists

\section{Report on the Asian disasters in Myanmar and China}

\section{The Cyclone Nargis disaster in Myanmar}

Cyclone Nargis (an Urdu word meaning daffodil) developed on 27 April 2008 in the central area of the Bay of Bengal. On 2 May 2008, with peak wind speeds of $215 \mathrm{~km} / \mathrm{h}$ (135 $\mathrm{mph}$ ), it moved ashore, leaving a trail of death and massive destruction. The death toll has now reached 100000 , with 56000 missing, and appears to be increasing. Responding to the disaster, the Asian Federation of Psychiatric Associations (AFPA) and South Asian Forum International joined forces with the Burmese Medical Association of Australia to bring relief and care. We have set up a crisis committee:

$O$ to assist and support the immediate medical care and treatment for all victims

o to support and enhance possible avenues to prevent infectious diseases

to provide physical and psychological support for the relief workers who are engaged in active disaster relief work

to facilitate capacity building and resilience promotion, including training of professionals in psychological assessment and mental health issues in recovery from disasters.

On 30 and 31 May 2008 the Asian Disaster Mental Health Network ran a training workshop for Burmese doctors and other professionals and volunteers who will be going to Myanmar to implement phases 2 and 3 of the recovery programme. On 29 August 2008 the Asian Disaster Network will run a symposium on recent Asian disasters at the 13th Psychiatric Congress of the Association of South East Asian Nations (ASAEN) in Bangkok. The Burmese Medical Association of Myanmar is sending a team of experts from the Asian Disaster Network to Myanmar for a series capacity-building activities.

Details for donations to the Burmese Doctors' Relief Fund are as follows: 